\title{
EFFECT OF USE OF PERSONAL HEARING PROTECTIVE DEVICES AMONG OIL DEPOT INDUSTRIAL WORKERS IN LAGOS, NIGERIA.
}

\author{
Journal website at; \\ http://mrtbjournal.org/index.php/njmr/issue/current/showToc \\ ABETAYE,SOER M,ABIODUNK \\ Department of Communication Pathology, Audiology Unit \\ Faculty of Humanities, University of Pretoria, \\ South Africa
}

\author{
Correspondence to: \\ Olusola Taye ABE \\ taye_abe@yahoo.com
}

\begin{abstract}
SUMMARY
Background: Noise-induced hearing loss is a major occupational health hazard (Hong $\mathrm{O}, 2005$ ). There is lack of use of hearing protectors to prevent noise- induced hearing loss in the oil industry in Nigeria. It poses great challenges to hearing conservation programmes among industrial workers and employers. Management of noise induced hearing loss and the use of hearing protection devices at work have not been given adequate attention.
\end{abstract}

Objective: The purpose of this study was to assess and establish the need for use of Personal hearing protectors in preventing noise-induced hearing loss in the oil industry.

Methods: The study employed experimental research design using ex-post facto type on a multinational oil service company in Lagos, Nigeria. Fifty respondents at the production section were randomly selected after inclusion. The respondents were divided into two groups of twenty five each. A sound level $130 \mathrm{~dB}$ was recorded at work place while respondents audiometric Pure Tone Average (PTA) was taken and analysed using differential statistics and t-test.

Results: A significant difference of hearing ability of hearing protector users and non- users was observed. Hearing protector users within the normal hearing level criteria increased from $48 \%$ to $56 \%$, while non-users within the normal hearing level criteria decreased from $52 \%$ to $32 \%$ after six months of noise exposure.
Conclusions: The greatest advantage may be achieved by educating the public on the hazardous effects of excessive noise exposure and need to initiate programmes for workers and employers on the importance of use of Personal hearing protective devices to prevent noise induced hearing loss among oil and gas industrial workers.

Key words: noise-induced, hearing, protective, conservation and devices.

\section{INTRODUCTION}

In today's complex industrial society, noise exposure poses an increasingly serious threat to individuals, hearing. $16 \%$ of hearing loss among adults has been attributed to occupational noise exposure. The effects are larger among males than females and higher in developing countries (Nelson et al., 2005). Occupational noise-induced hearing loss has been recognized as serious problem among workers (Patel \& Ingel, 2008). There are 28 million people in the United States with impaired hearing. Nearly ten million of these cases are associated with loud noise (ASHA, 1991). Over exposure to loud noise, damages hearing (Abe, 2000). Noise protection and hearing conservation should involve going to source of noise and conducting environmental far reaching discussions to combat the present day menace of loud noise in the oil \& gas industry, offices, public places shops and recreation centres. The first step in solving noise complaints is in a reasonable discussion. Audiometric testing of noise in exposed workers is mandatory in Singapore (Tay, 1996; Nelson, 2007).

The importance of hearing conservation to mankind 
particularly industrial workers is becoming increasingly important to oil and gas industry, public safety and health. Hearing is golden hence hearing protection is very significant in hearing conservation against noise-induced hearing loss. Noise-induced hearing loss cannot be cured, its prevention is crucial; hence Otolaryngologists and Audiologists should be aware of the various types of personal hearing protectors and their effective functionalities in respect of industrial over exposure to loud noise. Most developing countries have not introduced industrial workers to hearing protection (Alidrisi et al., 1993 and Obiako, 1990).

Occupational safety health and administration (OSHA) has standards that dictates the types and level of hearing protection required for various working environments depending on the intensity of noise exposure. OSHA regulatory body recommended hearing protection for time weighted average (TWA) of $85 \mathrm{~dB}$ and $90 \mathrm{~dB}$. If a worker experienced significant threshold shift even with $85 \mathrm{~dB}$ time weighted average hearing protection is still required regardless of the duration and in any area of unmeasured high noise level. The level of protection provided by a given hearing protector is specified by its noise- reduction rating (NRR). The workers' exposure Time weighted average for high noise level working environment, requires the wearing of earplugs and earmuffs all together. Hearing protector attenuate sound workers with hearing protectors find it easier to listen over a period of time. Proper insertion of earplugs in the ears is the only guarantee to efficacy of the earplugs. Earmuffs have higher noise reduction rating than earplugs.

Noise - induced hearing loss relates to both the sound duration and intensity on current allowable guidelines that for every $5 \mathrm{~dB}$ increase in the noise level the allowable duration is halved (Pelton, 1993 and Campbell, 1993). Occupational Safety Health and Administration criteria to protect workers from permanent threshold shifts (PTS) on noise - induced hearing loss.

Table 1. The Permissible Exposure Level (PEL)

\begin{tabular}{cc}
\hline Sound level (dBA) & Duration per Day (Hours) \\
\hline 80 & 32 \\
85 & 16 \\
90 & 8 \\
95 & 4 \\
100 & 2 \\
105 & 1 \\
110 & 0.5 \\
115 & 0.25 \\
\hline
\end{tabular}

Source: Occupational Safety and Health Administration (OSHA, 1993)

Recreational noise even though exposure is less frequent and shorter duration than occupational exposure nevertheless the noise generated are intense enough to damage hearing that could cause noise- induced hearing loss (Burtka and Chick 1997).
There are three types of personal hearing protection devices.

a. Earplugs; They are placed inside the ear canal to block out noise. The earplugs are either disposable or reusable plugs. The earplugs cut down or reduce noise by as much as $30 \mathrm{~dB}$.

b. Earmuffs; The earmuffs resemble stereo headphones with soft plastic cushions filled with foams or liquid to form good seal against noise. Earmuffs noise reduction rating is put as much as $25 \mathrm{~dB}$.

c. Canal caps; these are personal hearing protective devices with soft pads on a headband. It seals the ear canal without actually entering the ear canal. Canal caps are less effective compared to earplugs and earmuffs.

\section{Hypotheses.}

1. There is no significant difference between users of Personal hearing protective devices and non- users exposed to occupational loud noise.

2. There is no significant difference among non - users of personal hearing protective device exposed to loud noise in their workplace.

3. There is no significant difference in the hearing ability of users of personal hearing protective device exposed to noise in their workplace.

\section{MATERIAISAND METHODS}

The study employed experimental research design using the ex-post facto type. A well-structured exposure based auditory discrimination scale was used to randomly select the respondents among the oil service depot company workers in the production section in Lagos Nigeria for inclusion.

Respondents: The randomly selected respondents were divided into two different groups of users of personal hearing protective device and non users as control group. Overall, fifty respondents fit for the study was randomly selected into two groups of 25 each. 25 users of personal hearing protective device and the second study control group of 25 non users of Personal hearing protective device non-users. The two groups were exposed to the same noise level in the same production section in the oil service depot. The Sound level $120 \mathrm{~dB}$ reading of the noise exposure was taken by sound level metre.

Procedure: Data collection for this study lasted for a period of eight (8) weeks, i.e. the researcher used 4 weeks in each of the two groups. This study was carried out as stated in the Test Administration package but the data for analysis were collected via the following ways. The audiometric patterns of each group was taken and analyzed by finding the means and Standard deviation of the hearing threshold as a function of loud noise exposure. With this, the puretone audiometric threshold measures at 500, 1000, 2000 and $4000 \mathrm{HZ}$ were summarized and divided to get pure- 
tone average thresholds for the individual on both ears.

The slope of the pure-tone threshold pattern was calculated according to the method of Llyod and Kplan (1978), by averaging the difference between thresholds at octaves from 0.5 to $4 \mathrm{KzS}$. Also, the slopes of the workers audiograms were used to determine the influences of noise exposure on hearing abilities of the oil industrial workers. Pure Tone Audiometric Average (PTA) test for left and right ears established the hearing abilities of all the respondents after six months of noise exposure and use of Personal hearing protective devices. Data were analyzed using descriptive statistics, Analysis of Variance and $t$ test.

\section{RESULTS}

Table below shows the fifty respondents audiometric pure tone average results recorded for the two different groups before issuance of hearing protectors and after six months of noise exposure at the production section of the industry. to twenty five of the randomly selected workers.

The means of $\mathrm{x}=28 \mathrm{~dB}$ and $\mathrm{x}=27 \mathrm{~dB}$ for first and second test for personal hearing protective device users confirms hearing conservation and improvement of $1 \mathrm{~dB}$ Pure Tone Average (PTA) reduction, while the means scores for the non- users increased from $x=27 \mathrm{~dB}$ to $x=34 \mathrm{~dB}$.

The frequency and the percentages on table three revealed that only $32 \%$ of non-users of Personal hearing protective devices had normal hearing after six months while majority $56 \%$ of Personal hearing protective devices users were within normal hearing level. The percentage also shows $4 \%$ of severely hearing loss among non-users of Personal hearing protective devices.

Hypothesis one: There is no significant difference between personal protective hearing devices users and non- users. The mean $x=27.24$ decibel on table two above for personal hearing protective device users and $\mathrm{x}=34 \mathrm{~dB}$ for non-users with standard deviation of 13.20 and t-test 0.093 revealed significant difference in the reduction of noise impact on the hearing ability of the experimental group than the control group. The Pure tone average of users of personal hearing protective devices decreased while non- users increased after six months of noise exposure (users $x=28 \mathrm{~dB}$ $-27.24 \mathrm{~dB}$ and non-users $x=27 \mathrm{~dB}-\mathrm{x}=34 \mathrm{~dB}$ ). The difference was found to be significant. The non-users of PHPD had poorer hearing ability with a mean increase of mean $x=7 \mathrm{~dB}$ after six months of noise exposure than their counterpart with $x=.76 \mathrm{~dB}$ mean decrease exposed to same level of noise exposure in their workplace. On this basis the null hypothesis is hereby rejected and accepted that there was significant difference impact on the use of personal hearing protective device users and non - users.

Hypothesis two: There is no significant difference on effect of noise exposure among non - users of personal hearing protective device.

Table 2: Pure Tone Average for Users of Personal hearing protective devices (PHPD) and Non - users in Decibels (dB) for Left and Right ears.

\begin{tabular}{|c|c|c|c|c|c|c|c|}
\hline $\begin{array}{l}\text { Respondents } \\
\text { Test }\end{array}$ & $\begin{array}{l}\text { PHPD } \\
\text { USERS } \\
\text { PTA in dB }\end{array}$ & $\begin{array}{l}\text { PHPD } \\
\text { Non-Users } \\
\text { PTA in dB }\end{array}$ & $\begin{array}{l}\text { Difference } \\
\text { in PTA } \\
d B\end{array}$ & $\begin{array}{l}\text { Respondents } \\
\text { RE-TEST }\end{array}$ & $\begin{array}{l}\text { PHPD } \\
\text { Users } \\
\text { PTA in dB }\end{array}$ & $\begin{array}{l}\text { PHPD } \\
\text { Non-Users } \\
\text { PTA In dB }\end{array}$ & $\begin{array}{l}\text { Difference } \\
\text { PHPD users } \\
\text { and Non-users } \\
\text { InPTA d } \\
\end{array}$ \\
\hline 1 & 25 & 18 & 7 & 1 & 25 & 24 & 1 \\
\hline 2 & 30 & 24 & 6 & 2 & 28 & 30 & 2 \\
\hline 3 & 40 & 30 & 10 & 3 & 40 & 40 & 0 \\
\hline 4 & 50 & 16 & 34 & 4 & 45 & 25 & 20 \\
\hline 5 & 10 & 10 & 0 & 5 & 10 & 16 & -6 \\
\hline 6 & 5 & 12 & -7 & 6 & 5 & 20 & -15 \\
\hline 7 & 10 & 33 & -23 & 7 & 10 & 40 & -30 \\
\hline 8 & 15 & 42 & -27 & 8 & 15 & 45 & -30 \\
\hline 9 & 14 & 21 & -7 & 9 & 15 & 27 & -13 \\
\hline 10 & 20 & 34 & -4 & 10 & 20 & 40 & -20 \\
\hline 11 & 23 & 60 & -37 & 11 & 22 & 65 & -43 \\
\hline 12 & 30 & 28 & -20 & 12 & 28 & 30 & -2 \\
\hline 13 & 21 & 41 & -7 & 13 & 20 & 45 & -25 \\
\hline 14 & 28 & 20 & 8 & 14 & 30 & 30 & 0 \\
\hline 15 & 26 & 25 & 1 & 15 & 25 & 30 & -5 \\
\hline 16 & 45 & 30 & 15 & 16 & 45 & 40 & 5 \\
\hline 17 & 50 & 15 & 35 & 17 & 48 & 20 & 28 \\
\hline 18 & 60 & 20 & 40 & 18 & 55 & 25 & 30 \\
\hline 19 & 15 & 25 & 10 & 19 & 15 & 30 & -15 \\
\hline 20 & 30 & 16 & 16 & 20 & 20 & 20 & 0 \\
\hline 21 & 23 & 18 & 5 & 21 & 25 & 25 & 0 \\
\hline 22 & 42 & 30 & 12 & 22 & 40 & 35 & 5 \\
\hline 23 & 35 & 36 & -1 & 23 & 35 & 40 & -5 \\
\hline 24 & 42 & 40 & 2 & 24 & 40 & 45 & -5 \\
\hline$\underline{25}$ & 20 & 40 & -20 & 25 & 20 & 46 & -26 \\
\hline
\end{tabular}


Table 3: Distribution of the hearing loss of workers Pure Tone Average after six months of noise exposure.

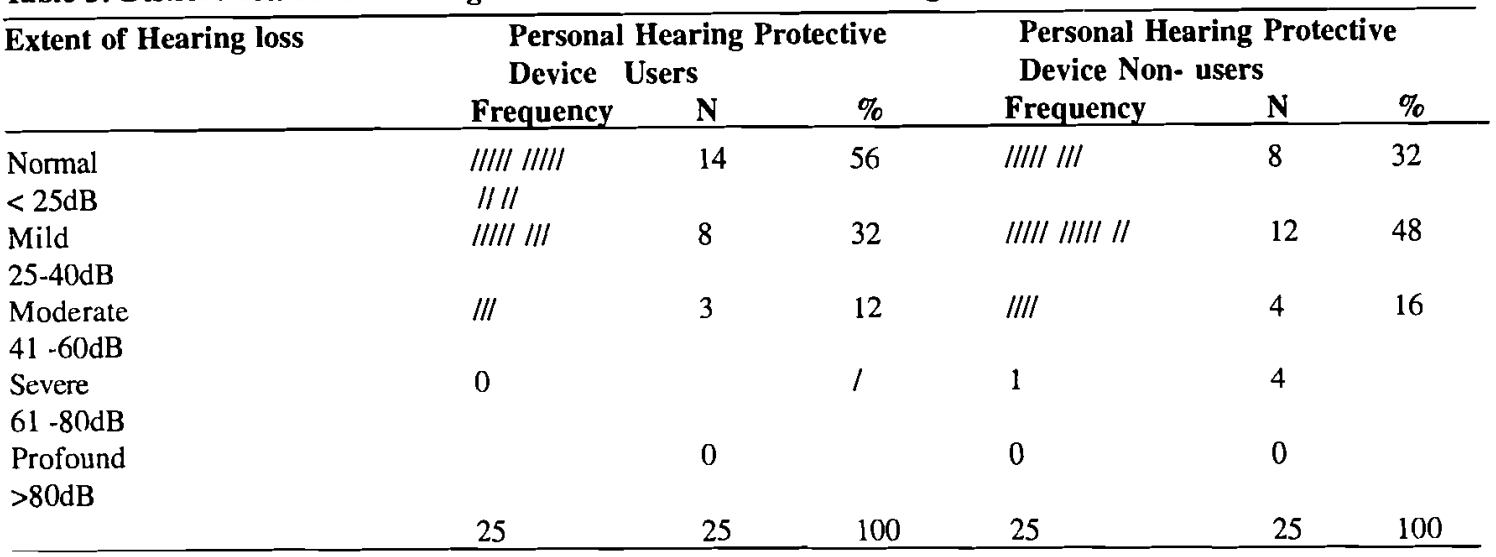

Table 4: Pure Tone Audiometric Average Test of Personal Hearing Protective Device Users and Nonusers or both left and right ears.

\begin{tabular}{|c|c|c|c|c|c|c|c|}
\hline \multirow[t]{2}{*}{$\begin{array}{l}\text { Sources of } \\
\text { variation }\end{array}$} & \multirow[t]{2}{*}{ No of cases } & \multicolumn{2}{|c|}{$\begin{array}{l}\text { Mean } \\
X\end{array}$} & \multirow[t]{2}{*}{$\begin{array}{l}\text { Standard } \\
\text { deviation }\end{array}$} & \multirow[t]{2}{*}{$\begin{array}{l}\text { Calculated } \\
t\end{array}$} & \multirow[t]{2}{*}{$\begin{array}{l}\text { Df } \\
\%\end{array}$} & \multirow[t]{2}{*}{$\mathbf{p}$} \\
\hline & & Pre-test & Post-test & & & & \\
\hline PHPD Users & 25 & $28 \mathrm{~dB}$ & $27.24 \mathrm{~dB}$ & 13.201 & 0.093 & 149 & 0.0935 \\
\hline PHPD Non-Users & 25 & $27 \mathrm{~dB}$ & $34 \mathrm{~dB}$ & 11.2202 & & & \\
\hline
\end{tabular}

Table 5: Pure Tone Average Test for of Personal Hearing Protective Device Non-Users for both left and right ears.

\begin{tabular}{lllllll}
\hline $\begin{array}{l}\text { Sources of } \\
\text { variation }\end{array}$ & No of cases & $\begin{array}{l}\text { Mean } \\
\mathbf{X}\end{array}$ & $\begin{array}{l}\text { Standard } \\
\text { deviation }\end{array}$ & $\begin{array}{l}\text { Calculated } \\
\mathbf{t}\end{array}$ & $\begin{array}{l}\text { Df } \\
\%\end{array}$ & $p$ \\
\hline PHPD Non-Users. & 25 & $27 \mathrm{~dB}$ & $34 \mathrm{~dB}$ & 11.22 & 0.0856 & 23.32 \\
\hline
\end{tabular}

Table 6: Pure Tone Audiometric Average Test for let and right ears of Personal hearing Protective device users.

\begin{tabular}{lllllll}
\hline $\begin{array}{l}\text { Sources of } \\
\text { variation }\end{array}$ & No of cases & $\begin{array}{l}\text { Mean } \\
\text { X } \\
\text { Post-test }\end{array}$ & $\begin{array}{l}\text { Standard } \\
\text { deviation }\end{array}$ & $\begin{array}{l}\text { Calculated } \\
\mathbf{t}\end{array}$ & $\begin{array}{l}\text { Df } \\
\%\end{array}$ & p \\
\hline PHPD Users & 25 & $28 \mathrm{~dB}$ & $27.24 \mathrm{~dB}$ & 17.482 & 0.08582 & 3 \\
\hline
\end{tabular}

Table 7: Personal hearing protective devices reduction ratings and cost prize per unit in dollars and naira.

\begin{tabular}{lcl}
\hline Type of hearing protectors & Noise reduction rating & Cost per unit \\
\hline Ear plugs & $30 \mathrm{~dB}$ & $\$ 20$ or $\mathrm{N} 3,175.00$ \\
Ear muffs & $25 \mathrm{~dB}$ & $\mathrm{~N} 60$ or $\mathrm{N} 6,350.00$ \\
Canal caps & $20 \mathrm{~dB}$ & $\$ 18$ or $\mathrm{N} 2,450.00$ \\
\hline
\end{tabular}

The pre-test mean score of $x=27 \mathrm{~dB}$ and post-test mean score of $x=34 d B$ shows

Significant percentage increase of $26 \%$ on both left and right ears of Personal hearing protective device non - users. This significant increase in the mean score of the nonusers of personal hearing protective device is in line with the hypothesized effect of exposure of an individual that the more the exposure to loud noise the more the impact of noise-induced degenerates from Temporary Threshold Shift to Permanent Threshold Shift (Berger, 2000). On the basis of this, the null hypothesis is hereby rejected and that there was significant difference and decrease in the hearing ability among non - users of personal hearing protective device exposed to loud noise in their place of work.

Hypothesis three: There is no significant difference in the hearing ability among users of personal hearing protective device exposed to loud noise in their work place.

The mean score of $x=27.24 \mathrm{~dB}$ post-test compared with 
pre-test mean score of $\mathrm{x}=28 \mathrm{~dB}$ revealed a significant decrease in the impact of noise exposure among Personal hearing protective device users after six months of issuance exposure to noise in their workplace. The hearing ability of the PHPD users improved by a decrease of $x=.76 \mathrm{~dB}$ an approximate of one decibel (IdB) for both left and right ears IdB. This post-test mean score 1996 represent 3\% improvement in the hearing ability of the oil workers exposed to noise. This corroborated Ganguly 1993 and recommendation of and the importance of hearing protection of workers exposed to loud noise. On the basis of the above, the null hypothesis three is hereby rejected and accepted that there was significant difference and improvement in the hearing ability of Personal Hearing Protective Device Users exposed to noise in their workplace.

\section{DISCUSSION}

The hearing ability for non-users of personal hearing protection Hearing Defenders (2003), Workplace Health Safety and Compensation (2003) claims that hearing protectors reduce or cut down noise by the following reduction ratings and cost per unit.

The result of the test shows significant difference between hearing protective users and the non- users. The finding confirms and corroborated the recommendation of Ganguly (1993) on the importance of use of hearing protectors by workers exposed to loud noise. This study further establishes that there is prevalence of hearing impairment among oil and gas workers exposed to loud noise over $80 \mathrm{~dB}$ without the use of hearing protective devices than those who used personal hearing protective devices at work. Public awareness of the hazardous effects of excessive noise should be initiated at an early stage to encourage appropriate behaviour on the workers and the employers.

The fact that available earmuffs used by the industrial workers could only cut down noise by $25 \mathrm{~dB}$ shows that the noise exposure levell $10 \mathrm{~dB}$ and mean score $35 \mathrm{~dB}$ measured at the place of work of the respondents clearly reveals that the noise exposure is capable of reducing the noise level by $86 \mathrm{~dB}$, than no reduction at all causing noiseinduced hearing loss. $110-25=85 \mathrm{~dB}$. This finding corroborated the Raja and Bhattachanya et al. (1990) and Sheikh (2007) advocating for use of hearing protection for workers exposed to occupational noise. Exposure to sound above $60 \mathrm{~dB}$ for a consecutive one hour is capable of causing $1 \mathrm{~dB}$ hearing loss (Pelton, 1997). All the respondents spent over nine hours per day at work which again violated the Permissible exposure level of Occupational Safety Health and Administration stipulated guidelines (OSHA, 1997) The workers spent nine hours at work against the stipulated guidelines of 30 minutes per day in exposure level of $95 \mathrm{~dB}$.

The study creates the opportunity for the industrialists of the need to determine whether noise levels generated in their factory exceed the damage risk criteria of permissible exposure level guidelines given by Occupational Safety Health and Administration stipulated guidelines. The study reveals the awareness for regular audiometric evaluation of their industrial workers in noisy environment and the importance of serious planning of hearing conservation programmes as adequate answer to overexposure to noise-induced hearing loss.

\section{CONCLUSION}

On the basis of the result obtained above, it is observed that government and the public now have opportunity of knowing deleterious effect of noise on the safety and health of man and the necessary precautions to be taken without paying lip service to environmental protection agency and noise control.

There should be regular public enlightenment by encouraging seminar and workshops on the effects of environmental noise pollution to human hearing organs.

It is of utmost importance that equipment source control and monitoring sound level would be the effective way to prevent overexposure to loud noise. Hearing aid provision and procurement also need to be given adequate attention for early intervention on noise-induced hearing loss workers. A model hearing conservation programmes need to include the following general components:

a. Noise exposure assessment in Nigeria oil and gas industry.

b. Mandatory audiometric test for oil and gas industrial workers.

c. Use of Personal Hearing protection device for workers exposed to more than $80 \mathrm{~dB}$ noise level.

d. Worker and management education and motivation.

e. Record keeping;

f. Analysis of programme effectiveness.

In addition, components of occupational hearing conservation programmes, Audiologist must be involved in forensic activities, such as serving as expert witness in hearing loss compensation claim cases and other forms of litigation.

There is need to follow general professional agreement that the Occupational Safety Health and administration regulations represent.

\section{REFERENCES}

- Abe A. (2000). overexposure to noise damage hearing. Indianapolis star. Indianapolis .pg. G01.

- Alidrisi M, Jamil ATM, Jiffry MSA \& Jeffri A. (1990). Evaluation of noise stresses in Jeddah Industrial Estate. $J$ Environ SCI Health A 25(8): 873-896.

- Asha (1995). The Audiologist's role in occupational Hearing Conservation; America Speech Language Hearing Association: 29CFR 1910.25; US. DOL, 981.

- Bhattacharya, S. Kasyyaps, S \& Tripahi, R. (1990), Heat and noise problems in a firm in a drug and pharmaceutical firm in India. Ind Health 28: 203-207. 
- Burtka C and Yarenchick K. (1997). Non- Industrial Noise levels London singular publishing group INC. Pg. 130. San Diago.

- Campbell K. (1997). Effect of single loud Noise London, Essential Audiology for physicians: singular publishing Group, INC: London Pg. 129-131.

- Campbell K. (1998). Essential Audiology for physician, singular publishing Group, INC. London .

- Nelson D, Nelson R, Concha-Barrietos, M \& Fingerhnt, M. (2005). The Global Burden of Occupational Noise-Induced Hearing Loss. Publication of American Journal of Industrial Medicine. Wiley-Liss Washington DC pp.1-15.

- Obiako M(1979). Deafness and the hearing level of miners in Zambia; East African Med. J. 56 (9): 445-449.

- Hong O (2005). Hearing loss among operating Engineers in America construction industry. Intern Arch. Occupational Environ Health.78: School of Nursing University of
Michigan; 565-574 DOI 10.1007/000420- 005-0623-9.

- Osha (1993). Permissible Exposure Levels singular publishing Group INC.pg. 23 pp 4: vol.5.

- Patel T \& Ingle S. (2008); Occupational noise exposure and hearing loss among pulse processing workers; Environmentalist; 28 :358-365 DOI 10.1007/S/ O669-0079148-Y.

- Pelton OA (1993). Permissible Exposure Level Campbell K. edited 1993. Essentials of Audiology for physicians pg. 128-129. Sandiego, singular.

- Raja, S and Gangulay, G. (1983). Impact of exposure to noise on the hearing acuity of employees in a heavy engineering industry: India J. Med. Res 78: 100-113.

- Tay, P, (1996), Audiometric testing of noise -exposed workers . Singapore Medicine J.:Singapore. Vol. 37: Pg. 362-364 